\title{
Diskussion
}

Helga Königsdorf: Lemma I (24-I)

Mit großer Freude las ich in den letzten DMV-Mitteilungen wieder einmal „Lemma I“. Aber bei den persönlichen Daten der Autorin ist ein kleiner Fehler unterlaufen: Helga ist eine geborene Königsdorf, verheiratete Bunke.

Am 13.7. 1938 wurde Helga Königsdorf in Gera geboren. Nach dem Abitur begann sie im Jahre 1955 ein Physikstudium an der Friedrich-Schiller-Universität in Jena. Im September 1956 zog die Familie nach Berlin. 1958 heiratete Helga Königsdorf den Mathematiker Olaf Bunke, den Bruder von Tamara Bunke (bekannt als „Tanja la Guerrillera“, der Mitstreiterin von Ernesto "Che“ Guevara).

Sie promovierte 1963 und habilitierte 1972 auf dem Gebiet der Gewöhnlichen Differentialgleichungen. 1974 wurde sie zur Professorin an die Akademie der Wissenschaften in Berlin berufen. In dieser Zeit machte sich auch ihre Parkinsonsche Erkrankung bemerkbar.

1978 erscheint der Geschichtenband Meine ungehörigen Träume. Es folgten Der Lauf der Dinge (1982) und Mit Klischmann im Regen (1983). Viele weitere Bücher folgen. Helga Königsdorf wird geehrt mit der Verdienstmedaille der DDR, dem Heinrich-MannPreis, dem Nationalpreis.

Sie engagiert sich in den Revolutionen des Jahres 1989, wird nicht sprachlos. Ihre Protokolle der Ereignisse sind Zeitzeugnisse. Helga Königsdorf reist, liest, engagiert sich. Schreiben ist ihre Art der Auseinandersetzung mit der Politik und der Krankheit. Darum sagt sie: „Das Alter habe ich mir ganz anders gedacht. Als etwas Behagliches, Ruhiges, als etwas, wo man die Beine baumeln lassen kann." Sie stirbt am 4. Mai 2014 in Berlin.

Das Zusammentreffen von Mathematik und Poesie kommt in einem kleinen Dialog von Helga Königsdorf treffend zum Ausdruck: „Worin besteht der Sinn des Lebens“, fragte der kleine Prinz. Der Philosoph antwortete: „Der Sinn des Lebens besteht darin, den Gesetzen der Wahrscheinlichkeitsrechnung zum Durchbruch zu verhelfen."

Dieter Bauke

\section{Die Gauß-Vorlesungen der DMV (24-2)}

Der Autor informiert über die verdienstvollen Gauß-Vorlesungen der DMV seit 2002 und reproduziert die Programmflyer. In diesen werden die historischen Vorträge von wenigstens einer halben Stunde Länge, die den Hauptvorträgen vorangehen, niemals erwähnt. Diese Praxis ist ganz anders als im Fall der Euler- und der Weierstraß-Vorlesungen, wie man der Website der DMV entnehmen kann. Das Informationsbedürfnis der interessierten Teilnehmer, der Respekt vor der Arbeit der historisch Vortragenden, nicht zuletzt der Titel der Vorlesungsreihe legen es meines Erachtens nahe, dass sich die Gauß-Vorlesungen dieser anderen Praxis künftig anschließen. Niemand hat wahrscheinlich Einwände dagegen, wenn die „Vor-Vorträge“ im Kleindruck erscheinen.

Reinhard Siegmund-Schultze (Kristiansand, Norwegen)

\section{Curiosa XIV}

Mittels einer Münze und eines Lineals die Mittelsenkrechte einer Strecke zu bestimmen

Ist $A B$ die gegebene Strecke, so wählt man irgend einen Punkt $C$ zwischen $A$ und $B$ auf $A B$ und legt die Münze einmal so, da $B$ ihr Rand durch $A$ und $C$ geht, dann so, daß ihr Rand durch $B$ und $C$ geht. Beide Male zieht man den Rand nach. Die beiden Kreise treffen sich außer in $C$ in einem Punkt $D$. Dieser Punkt $D$ gehört der Mittelsenkrechten von $A B$ an; denn die Peripheriewinkel $\angle C A D$ und $\angle C B D$ sind sicher gleich. Man kann ebenso ein zweites Mal vorgehen, indem man statt $C$ einen anderen Punkt zwischen $A$ und $B$ benutzt oder auch, wie es in der Figur angedeutet ist, die Münze auf die zweite Art so legt, da $ß$ ihr Rand einmal durch $A$ und $C$, das andere Mal durch $B$ und $C$ geht. Dadurch ergibt sich ein zweiter Punkt $E$ der Mittelsenkrechten, die dann mit dem Lineal gezogen werden kann.

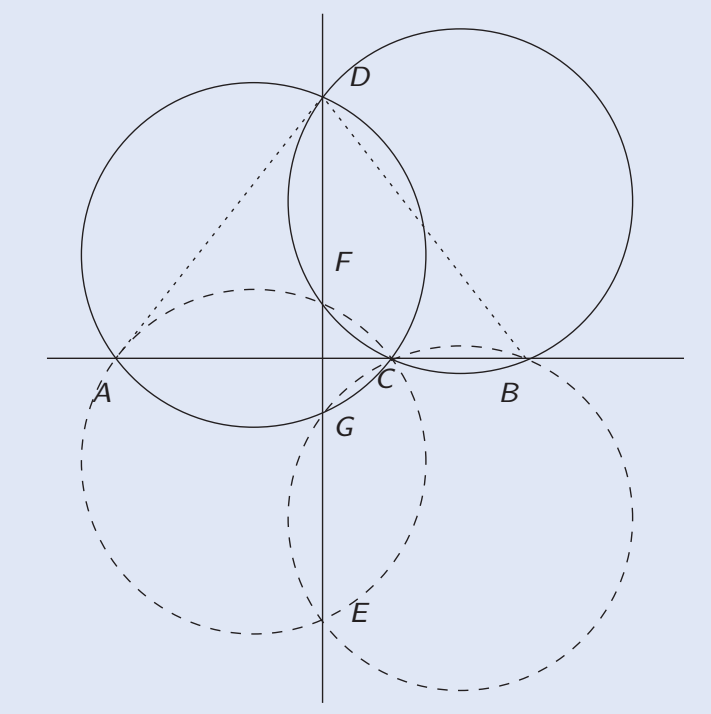

Wenn man wie in der Figur den Punkt $C$ auch für die zweite Konstruktion beibehält, bekommt man sogar insgesamt vier Punkte $D, E, F, G$ der Mittelsenkrechten.

Ist $A B$ größer als der Durchmesser der Münze, so versagt das Verfahren.

Man beachte: Im Schlusssatz des Textes müsste es korrekt ,.. der doppelte Durchmesser ... “, heißen. Zu Scheffers siehe auch www-history.mcs.st-andrews.ac.uk/Biographies/Scheffers.html Ulrich Warnecke 